\title{
Optimal Pricing and Ordering Policy for Deteriorating Items with Stock-and-Price Dependent Demand and Presale Rebate
}

\author{
Lianxia Zhao ${ }^{1}$ and Jianxin You ${ }^{2}$ \\ ${ }^{1}$ School of Management, Shanghai University, Shanghai 200444, China \\ ${ }^{2}$ School of Economic and Management, Tongji University, Shanghai 200092, China \\ Correspondence should be addressed to Lianxia Zhao; zhaolianxia@staff.shu.edu.cn
}

Received 2 August 2016; Accepted 3 November 2016

Academic Editor: Xinchang Wang

Copyright (C) 2016 L. Zhao and J. You. This is an open access article distributed under the Creative Commons Attribution License, which permits unrestricted use, distribution, and reproduction in any medium, provided the original work is properly cited.

\begin{abstract}
This paper considers an EOQ inventory model with presale policy for deteriorating items, in which the demand rate depends on both on-hand inventory and selling price. Under the assumption that all the presale orders are fully backlogged with waiting-time dependent rebate, this study develops several propositions and derives optimal pricing and ordering policy by designing an effective algorithm. Two numerical examples are also given to illustrate the effectiveness of the algorithm. Finally, the sensitivity analysis of the main parameters is provided.
\end{abstract}

\section{Introduction}

A large number of products have deteriorating property which manifests the decay or devaluation. This kind of products has much shorter life cycle, for example, some seasonal fresh products that cannot be stored for a long time even in modern storage conditions, electronic products with a fast updating speed, and fashion clothing. These products should be sold in a much shorter spot-sale period to reduce deteriorating cost and holding cost. Presale policy is an effective marketing strategy to reduce the spot-sale period, which is that customers are encouraged to order in advance to get a rebate related to the preorder time. All the orders will be satisfied when the products launch into the market. In addition, it is crucial to find out what factors mostly impact the demand of product, so we can decide proper ordering quantity.

It is obvious that the price of product highly influences the demand rate; thus the pricing for the product plays an important role in marketing strategy. Meanwhile, the stock level of product can also affect the demand rate. Many researchers have focused on such topic. Hou and Lin [1] considered an EOQ inventory model for deteriorating items with price-and-stock dependent selling rate, in which the proposed model allowed shortage and complete backorder while the shortage cost is constant. You and Hsieh [2] developed an inventory model for a seasonal item over a finite planning time by determining the optimal ordering quantity and price setting/changing strategy. Chang et al. [3] studied the optimal selling price and order quantity under EOQ model for deteriorating items, and the demand depends on the selling price and stock on display. Dye and Hsieh [4] developed an inventory model for deteriorating items with demand rate depending on selling price and stock, and shortages are allowed with the backlogging rate to be a decreasing function of the waiting time, while Giri and Bardhan [5] studied an integrated single-manufacturer and single-retailer supply chain model for deteriorating items with stock-and-price dependent demand. Relevant references can be found in Teng and Chang [6], Panda et al. [7], and so forth. Furthermore, more inventory models for deteriorating items with a variety of demand rate are summarized in Table 1. The difference between the relevant references and our study can be found in the table.

In our study, presale rebate depending on waiting time is given to encourage customers to order in advance. Although presale rebate cost is similar in form to the traditional shortage cost, it is different in meaning; moreover, the presale rebate cost in this paper is more complex and realistic than the traditional shortage cost which is generally considered to 
TABLE 1: Our paper versus literatures for key assumptions of inventory models with deteriorating items.

\begin{tabular}{|c|c|c|c|c|c|}
\hline Author/authors & Demand rate & Deterioration rate & Shortage or not & Shortage cost & Decision variable $^{*}$ \\
\hline Skouri et al. [8] & Time-dependent & Weibull distribution & Yes & Constant & $t, T$ \\
\hline Sicilia et al. [9] & Time-dependent & Constant & Yes & Constant & $t, T$ \\
\hline Cheng et al. [10] & Time-dependent & Constant & Yes & Constant & $t$ \\
\hline Zhao $[11,12]$ & Time-dependent & Weibull distribution & Yes & Constant & $t$ \\
\hline Begum et al. [13] & Price-dependent & Weibull distribution & No & No & $p, T$ \\
\hline Dye [14] & Price-dependent & Time-dependent & Yes & Constant & $p, t$, and $T$ \\
\hline Yang et al. [15] & Price-dependent & No & Yes & Constant & $t, T$ \\
\hline B. Sarkar and S. Sarkar [16] & Stock-dependent & Time-dependent & Yes & Constant & $t, T$ \\
\hline Padmanabhan and Vrat [17] & Stock-dependent & Constant & Yes & Constant & $t, T$ \\
\hline Avinadav et al. [18] & Price-and-time & Constant & No & No & $p, Q$, and $T$ \\
\hline Maihami and Nakhai Kamalabadi [19] & Price-and-time & Noninstantaneous & Yes & Constant & $p, T$ \\
\hline Hou and Lin $[1]$ & Price-and-stock & Constant & Yes & Constant & $t, T$ \\
\hline Giri and Bardhan [5] & Price-and-stock & No & No & No & $t, n$ \\
\hline This paper & Price-and-stock & Constant & Presale & Time-dependent & $p, t$, and $T$ \\
\hline
\end{tabular}

${ }^{*} p=$ selling price, $t=$ replenishment/out of stock time, $Q=$ order quantity, $T=$ inventory cycle, and $n=$ the number of replenishment.

be constant. In addition, we assume the demand is price-andstock dependent according to the actual situation. Eventually, we derive optimal pricing and ordering policy by designing an effective algorithm and provide the sensitivity analysis of the parameters to assess their effects on the optimal policy.

The rest of the paper is organized as follows: we introduce some basic notations and assumptions in Section 2. Section 3 establishes an inventory model under presale policy and provides an effective procedure to find the optimal pricing and presale strategy. In Section 4, we use several numerical examples to illustrate the procedure of the optimal strategies and analyze the sensitivity of parameters involved. Finally, we provide a summary of the paper.

\section{Notation and Assumptions}

The fundamental notation and assumptions used in this paper are given as below.

\subsection{Notation}

$c_{p}$ : the purchase price of unit item;

$A_{0}$ : the fixed cost per order;

$S$ : the maximum inventory level;

Q: the ordering quantity;

$p$ : the selling price of unit item

$\theta$ : the constant deteriorating rate, $0 \leq \theta \ll 1$;

$t_{1}$ : presale period;

$t_{2}$ : spot-sale period;

$I(t)$ : the level of inventory at time $t, 0 \leq t \leq T$, where $T=t_{1}+t_{2}$;

$c_{d}$ : the cost of each deteriorated item;

$c_{h}$ : the inventory holding cost per unit per time;

$D(t, p)$ : the demand rate; $c_{s}(x)$ : the presale rebate cost;

$\prod\left(t_{1}, t_{2}, p\right)$ : the average total profit per unit time.

\subsection{Assumptions}

(i) The replenishment rate is infinite; that is, replenishment is instantaneous.

(ii) Assume the customers are loyal, and all the presale orders will not be canceled until the products are launched into the market.

(iii) The demand rate, $D(t, p)$ : we assumed it to be

$$
D(t, p)= \begin{cases}g(p), & 0 \leq t \leq t_{1} \\ g(p)+\alpha I(t), & t_{1} \leq t \leq T\end{cases}
$$

where $g(p)$ is a function of $p, g^{\prime}(p)<0$, and $g^{\prime \prime}(p) \geq$ 0 , where $\alpha$ denotes the stock-dependent consumption rate.

(iv) $c_{s}(x)$ is the presale rebate determined by the waiting time $x$; that is, $c_{s}(x)=c_{0}\left(e^{\lambda x}-1\right)$, where $c_{0}$ is positive constant and $\lambda \in(0,1)$.

(v) The marginal gross profit with respect to price is decreasing; that is, $\left(p-c_{p}\right) g(p)$ is a strictly concave function of $p$.

\section{Inventory Model with Presale Policy}

In this section, we consider an inventory model with presale policy for deteriorating items, and the behavior of the system is depicted in Figure 1. From $t=0$ to $t_{1}$, the total presale quantity accumulates on account of demand which is fully backlogged and achieves its maximum at time $t=t_{1}$. During the time interval $\left[t_{1}, t_{1}+t_{2}\right)$, due to customers' demand and deterioration, on-hand inventory level gradually decreases to 


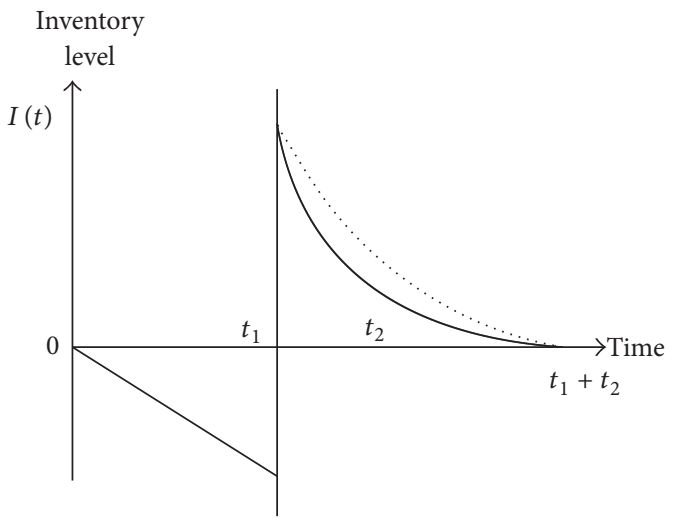

FIGURE 1: Graphical representation of inventory level over the cycle.

zero. According to the above notations and assumptions, such inventory system can be described by following differential equations:

$$
\begin{aligned}
& \frac{d I(t)}{d t}=-g(p) \quad 0 \leq t \leq t_{1} \\
& \frac{d I(t)}{d t}=-\theta I(t)-g(p)-\alpha I(t) \quad t_{1} \leq t \leq t_{1}+t_{2} .
\end{aligned}
$$

With boundary condition $I(0)=0, I\left(t_{1}+t_{2}\right)=0$.

The solution of (2) can be obtained as

$$
\begin{aligned}
& I(t)=-g(p) t \quad 0 \leq t \leq t_{1}, \\
& I(t)=\frac{g(p)}{\alpha+\theta}\left(e^{(\alpha+\theta)\left(t_{1}+t_{2}-t\right)}-1\right) \quad t_{1} \leq t \leq t_{1}+t_{2} .
\end{aligned}
$$

The maximum inventory level per cycle is

$$
I\left(t_{1}^{+}\right)=\frac{g(p)}{\alpha+\theta}\left(e^{(\alpha+\theta) t_{2}}-1\right)
$$

The presale quantity per cycle is

$$
I\left(t_{1}^{-}\right)=-g(p) t_{1}
$$

The ordering quantity over the inventory cycle is

$$
Q=I\left(t_{1}^{+}\right)-I\left(t_{1}^{-}\right)=\frac{g(p)}{\alpha+\theta}\left(e^{(\alpha+\theta) t_{2}}-1\right)+g(p) t_{1} .
$$

Based on (3), the total cost per cycle consists of the following elements:

(i) Ordering cost $A_{0}$.

(ii) Purchase cost

$$
c_{p}\left[\frac{g(p)}{\alpha+\theta}\left(e^{(\alpha+\theta) t_{2}}-1\right)+g(p) t_{1}\right] .
$$

(iii) Sales revenue

$$
p\left[g(p) t_{1}+\int_{t_{1}}^{t_{1}+t_{2}}(g(p)+\alpha I(t)) d t\right] .
$$

(iv) Deteriorating cost

$c_{d}\left[\frac{g(p)}{\alpha+\theta}\left(e^{(\alpha+\theta) t_{2}}-1\right)-\int_{t_{1}}^{t_{1}+t_{2}}(g(p)+\alpha I(t)) d t\right]$.

(v) Holding cost

$$
\frac{c_{h} g(p)}{\alpha+\theta} \int_{t_{1}}^{t_{1}+t_{2}}\left(e^{(\alpha+\theta)\left(t_{1}+t_{2}-t\right)}-1\right) d t
$$

(vi) Presale rebate cost

$$
c_{0} g(p) \int_{0}^{t_{1}}\left(e^{\lambda\left(t_{1}-1\right)}-1\right) t d t
$$

Therefore, the total profit per unit time of the model can be obtained as follows:

$$
\prod\left(t_{1}, t_{2}, p\right)=\frac{1}{t_{1}+t_{2}}[\text { sales revenue }- \text { holding cost }
$$

- ordering cost - presale rebate cost

- deteriorated items cost - purchase cost]

$$
\begin{aligned}
& =-\frac{g(p)}{t_{1}+t_{2}}\left\{\frac{\Delta}{(\alpha+\theta)^{2}}\left(e^{(\alpha+\theta) t_{2}}-1\right)\right. \\
& +\frac{c_{0}}{\lambda^{2}}\left(e^{\lambda t_{1}}-\frac{1}{2} \lambda^{2} t_{1}^{2}-\lambda t_{1}-1\right)-\left(p-c_{p}\right) t_{1} \\
& \left.-\frac{1}{\alpha+\theta}\left(p \theta+c_{h}+c_{d} \theta\right) t_{2}\right\}-\frac{A_{0}}{t_{1}+t_{2}},
\end{aligned}
$$

where $\Delta=c_{h}+(\alpha+\theta) c_{p}+c_{d} \theta-p \alpha$.

Taking the first-order partial derivative of $\prod\left(t_{1}, t_{2}, p\right)$ with respect to $t_{1}, t_{2}$, and $p$, respectively, we have

$$
\begin{aligned}
& \frac{\partial \prod\left(t_{1}, t_{2}, p\right)}{\partial t_{1}}=-\frac{\prod\left(t_{1}, t_{2}, p\right)}{t_{1}+t_{2}}+\frac{g(p)}{t_{1}+t_{2}}\left[\left(p-c_{p}\right)\right. \\
& \left.-\frac{c_{0}}{\lambda}\left(e^{\lambda t_{1}}-\lambda t_{1}-1\right)\right], \\
& \frac{\partial \prod\left(t_{1}, t_{2}, p\right)}{\partial t_{2}}=-\frac{\prod\left(t_{1}, t_{2}, p\right)}{t_{1}+t_{2}} \\
& +\frac{g(p)}{t_{1}+t_{2}}\left[\frac{p \theta+c_{h}+c_{d} \theta}{\alpha+\theta}-\frac{\Delta}{\alpha+\theta} e^{(\alpha+\theta) t_{2}}\right],
\end{aligned}
$$

$$
\begin{aligned}
& \frac{\partial \prod\left(t_{1}, t_{2}, p\right)}{\partial p}=\frac{1}{t_{1}+t_{2}}\left\{\frac { g ( p ) \alpha - g ^ { \prime } ( p ) \Delta } { ( \alpha + \theta ) ^ { 2 } } \left[e^{(\alpha+\theta) t_{2}}\right.\right. \\
& \left.-(\alpha+\theta) t_{2}-1\right]-\frac{c_{0} g^{\prime}(p)}{\lambda^{2}}\left(e^{\lambda t_{1}}-\frac{1}{2} \lambda^{2} t_{1}^{2}-\lambda t_{1}\right. \\
& -1)\}+g(p)+g^{\prime}(p)\left(p-c_{p}\right) .
\end{aligned}
$$


For any given selling price $p$, the optimal solution $\left(t_{1}^{*}, t_{2}^{*}\right)$ is determined by the following equations:

$$
\begin{aligned}
& \frac{\partial \prod\left(t_{1}, t_{2}, p\right)}{\partial t_{1}}=0, \\
& \frac{\partial \prod\left(t_{1}, t_{2}, p\right)}{\partial t_{2}}=0 .
\end{aligned}
$$

By simplifying (14), we have

$$
\begin{aligned}
& \prod\left(t_{1}, t_{2}, p\right)-g(p)\left[\left(p-c_{p}\right)-\frac{c_{0}}{\lambda}\left(e^{\lambda t_{1}}-\lambda t_{1}-1\right)\right] \\
& =0 \\
& \prod\left(t_{1}, t_{2}, p\right)-g(p)\left[\frac{p \theta+c_{h}+c_{d} \theta}{\alpha+\theta}-\frac{\Delta}{\alpha+\theta} e^{(\alpha+\theta) t_{2}}\right] \\
& =0 .
\end{aligned}
$$

From the analysis of (15) and (16), we have the following propositions.

Proposition 1. For any given price $p$, (i) if $\Delta \leq 0$, then there does not exist any optimal solution $\left(t_{1}, t_{2}\right)$ so as to maximize the profit $\Pi\left(t_{1}, t_{2}, p\right)$; (ii) if $\Delta>0$, then the optimal solution $\left(t_{1}^{*}, t_{2}^{*}\right)$ which solves (15) and (16) simultaneously not only exists but also is unique.

Proof. (i) From (15) and (16), we have

$$
\frac{\Delta}{\alpha+\theta}\left(e^{(\alpha+\theta) t_{2}}-1\right)=\frac{c_{0}}{\lambda}\left(e^{\lambda t_{1}}-\lambda t_{1}-1\right)
$$

If $\Delta<0$, it is obvious that there does not exist any nonzero feasible solution to satisfy (17), which means that the optimal solution of the maximum profit $\prod\left(t_{1}, t_{2} \mid p\right)$ does not exist.

If $\Delta=0$, by solving (17), we have $t_{1}=0$. Substituting it into (16), we have $\prod\left(0, t_{2}, p\right)=\left(\left(p \theta+c_{h}+c_{d} \theta\right) /(\alpha+\right.$ $\theta)) g(p)$. Thus, from (12), we obtain $A_{0}=0$, which means a contradictory. Therefore, if $\Delta<0$, there does not exist any optimal solution $\left(t_{1}, t_{2}\right)$ to minimize the profit $\prod\left(t_{1}, t_{2} \mid p\right)$.

(ii) Let

$$
f(x)=\frac{\Delta}{\alpha+\theta}\left(e^{(\alpha+\theta) x}-1\right)-\frac{\mathcal{c}_{0}}{\lambda}\left(e^{\lambda t_{1}}-\lambda t_{1}-1\right) .
$$

Taking the first-order derivative of (18) with respect to $x$, it yields

$$
f^{\prime}(x)=\Delta e^{(\alpha+\theta) x} \geq 0
$$

which means that $f(x)$ is a nondecreasing function in $[0,+\infty)$.

Similarly, we know that the right hand-side of (17) is a strictly increasing function of $t_{1}$ and goes to infinite as $t_{1} \rightarrow$ $\infty$.

On the other hand, from (17), we have $\Delta e^{(\alpha+\theta) t_{2}}\left(d t_{2} /\right.$ $\left.d t_{1}\right)=c_{0}\left(e^{\lambda t_{1}}-1\right)>0$, which means $d t_{2} / d t_{1}>0$, and

$$
t_{2}=\frac{1}{\alpha+\theta} \ln \left[\frac{(\alpha+\theta) c_{0}}{\lambda \Delta}\left(e^{\lambda t_{1}}-\lambda t_{1}-1\right)+1\right] \text {. }
$$

Therefore, for any given $\tilde{t}_{1}$, there exists a unique $\tilde{t}_{2}$ such that $\tilde{t}_{2}=(1 /(\alpha+\theta)) \ln \left[\left((\alpha+\theta) c_{0} / \lambda \Delta\right)\left(e^{\lambda \tilde{t}_{1}}-\lambda \tilde{t}_{1}-1\right)+1\right]$.

To prove the uniqueness of the solution, substitute (12) into (15), and let

$$
\begin{gathered}
F\left(t_{1}\right)=-g(p)\left[\frac{\Delta}{(\alpha+\theta)^{2}}\left(e^{(\alpha+\theta) t_{2}}-1\right)+\left(p-c_{p}\right) t_{2}\right. \\
\left.-\frac{t_{2}}{\alpha+\theta}\left(p \theta+c_{h}+c_{d} \theta\right)\right]-A_{0}-\frac{c_{0} g(p)}{\lambda^{2}}\left[e^{\lambda t_{1}}\right. \\
\left.-\frac{1}{2} \lambda^{2} t_{1}^{2}-\lambda t_{1}-1-\lambda\left(e^{\lambda t_{1}}-\lambda t_{1}-1\right)\left(t_{1}+t_{2}\right)\right] .
\end{gathered}
$$

Taking the first-order derivative of $F\left(t_{1}\right)$ with respect to $t_{1}$, we have

$$
\begin{aligned}
& \frac{d F\left(t_{1}\right)}{d t_{1}}=-\frac{\Delta g(p)}{(\alpha+\theta)}\left(e^{(\alpha+\theta) t_{2}}-1\right) \frac{d t_{2}}{d t_{1}} \\
& +\frac{c_{0} g(p)}{\lambda}\left[\left(e^{\lambda t_{1}}-\lambda t_{1}-1\right) \frac{d t_{2}}{d t_{1}}\right. \\
& \left.+\lambda\left(e^{\lambda t_{1}}-1\right)\left(t_{1}+t_{2}\right)\right]=c_{0} g(p)\left(e^{\lambda t_{1}}-1\right)\left(t_{1}\right. \\
& \left.+t_{2}\right) \geq 0
\end{aligned}
$$

which means that $F\left(t_{1}\right)$ is an increasing function in $[0,+\infty)$. Using (17), it deduces $t_{2}=0$ as $t_{1}=0$; then we have $F(0)=$ $-A_{0}<0$ and $\lim _{t_{1} \rightarrow+\infty} F\left(t_{1}\right)=+\infty$. With the Intermediate Value Theorem, we can find a unique root $t_{1}^{*} \in[0,+\infty)$ such that $F\left(t_{1}^{*}\right)=0$.

From the above analysis, it is concluded that if $\Delta>$ 0 , the optimal solution $\left(t_{1}^{*}, t_{2}^{*}\right)$ which solves (15) and (16) simultaneously not only exists but also is unique.

Proposition 2. For any given $p$, the solution $\left(t_{1}^{*}, t_{2}^{*}\right)$ of (15) and (16) simultaneously is the global maximum of the profit per unit time.

Proof. Taking the second-order partial derivative of $\prod\left(t_{1}, t_{2} \mid\right.$ $p$ ) with respect to $t_{1}$ and $t_{2}$, respectively, we have

$$
\begin{aligned}
& \left.\frac{\partial^{2} \prod\left(t_{1}, t_{2} \mid p\right)}{\partial t_{1}^{2}}\right|_{\left(t_{1}, t_{2}\right)=\left(t_{1}^{*}, t_{2}^{*}\right)}=-\frac{c_{0} g(p)}{t_{1}^{*}+t_{2}^{*}}\left(e^{\lambda t_{1}^{*}}-1\right) \\
& <0, \\
& \left.\frac{\partial^{2} \prod\left(t_{1}, t_{2} \mid p\right)}{\partial t_{2}^{2}}\right|_{\left(t_{1}, t_{2}\right)=\left(t_{1}^{*}, t_{2}^{*}\right)}=-\frac{\Delta g(p)}{t_{1}^{*}+t_{2}^{*}} e^{(\alpha+\theta) t_{2}^{*}}<0, \\
& \left.\frac{\partial^{2} \prod\left(t_{1}, t_{2} \mid p\right)}{\partial t_{1} \partial t_{2}}\right|_{\left(t_{1}, t_{2}\right)=\left(t_{1}^{*}, t_{2}^{*}\right)}=0 .
\end{aligned}
$$


Then, the Hessian matrix satisfies

$$
\begin{aligned}
|H|= & \left.\frac{\partial^{2} \prod\left(t_{1}, t_{2} \mid p\right)}{\partial t_{1}^{2}}\right|_{\left(t_{1}, t_{2}\right)=\left(t_{1}^{*}, t_{2}^{*}\right)} \\
& \times\left.\frac{\partial^{2} \prod\left(t_{1}, t_{2} \mid p\right)}{\partial t_{2}^{2}}\right|_{\left(t_{1}, t_{2}\right)=\left(t_{1}^{*}, t_{2}^{*}\right)} \\
& -\left[\left.\frac{\partial^{2} \prod\left(t_{1}, t_{2} \mid p\right)}{\partial t_{1} \partial t_{2}}\right|_{\left(t_{1}, t_{2}\right)=\left(t_{1}^{*}, t_{2}^{*}\right)}\right]^{2}>0 .
\end{aligned}
$$

Therefore, we conclude that the stationary point $\left(t_{1}^{*}, t_{2}^{*}\right)$ is a global optimal solution for the considered problem.

In the following, we will show that the optimal selling price also exists and is unique for the problem.

Proposition 3. For any given $\left(t_{1}, t_{2}\right)$, there exists a unique optimal selling price such that $\prod\left(p \mid t_{1}, t_{2}\right)$ is maximized.

Proof. For any given $t_{1}$ and $t_{2}$, the first-order derivation of $\prod\left(p \mid t_{1}, t_{2}\right)$ with respect to $p$ is

$$
\begin{aligned}
& \frac{d \prod\left(p \mid t_{1}, t_{2}\right)}{d p} \\
& =\frac{1}{t_{1}+t_{2}}\left\{\frac { g ( p ) \alpha - g ^ { \prime } ( p ) \Delta } { ( \alpha + \theta ) ^ { 2 } } \left[e^{(\alpha+\theta) t_{2}}\right.\right. \\
& \left.-(\alpha+\theta) t_{2}-1\right]-\frac{c_{0} g^{\prime}(p)}{\lambda^{2}}\left(e^{\lambda t_{1}}-\frac{1}{2} \lambda^{2} t_{1}^{2}-\lambda t_{1}\right. \\
& -1)\}+g(p)+g^{\prime}(p)\left(p-c_{p}\right) .
\end{aligned}
$$

Because $g^{\prime}(p)<0$, we have $g(p) \alpha-g^{\prime}(p) \Delta>0$. Thus, $d \prod(p \mid$ $\left.t_{1}, t_{2}\right) / d p=0$ provides a solution only if $g(p)+\left(p-c_{p}\right) g^{\prime}(p)<$ 0 .

$$
\begin{aligned}
& \text { Let } \\
& \begin{array}{l}
G(p)=\frac{1}{t_{1}+t_{2}}\left\{\frac { g ( p ) \alpha - g ^ { \prime } ( p ) \Delta } { ( \alpha + \theta ) ^ { 2 } } \left[e^{(\alpha+\theta) t_{2}}\right.\right. \\
\left.-(\alpha+\theta) t_{2}-1\right]-\frac{c_{0} g^{\prime}(p)}{\lambda^{2}}\left(e^{\lambda t_{1}}-\frac{1}{2} \lambda^{2} t_{1}^{2}-\lambda t_{1}\right. \\
-1)\}+g(p)+g^{\prime}(p)\left(p-c_{p}\right) .
\end{array}
\end{aligned}
$$

Since the gross profit $g(p)\left(p-c_{p}\right)$ is a strictly concave function of $p$, which means $2 g^{\prime}(p)+g^{\prime \prime}(p)\left(p-c_{p}\right)<0$, we have

$$
\begin{aligned}
& G^{\prime}(p)=\frac{1}{t_{1}+t_{2}}\left\{\frac { g ^ { \prime } ( p ) \alpha - g ^ { \prime \prime } ( p ) \Delta } { ( \alpha + \theta ) ^ { 2 } } \left[e^{(\alpha+\theta) t_{2}}\right.\right. \\
& \left.-(\alpha+\theta) t_{2}-1\right]-\frac{c_{0} g^{\prime \prime}(p)}{\lambda^{2}}\left(e^{\lambda t_{1}}-\frac{1}{2} \lambda^{2} t_{1}^{2}-\lambda t_{1}\right. \\
& -1)\}+2 g^{\prime}(p)+g^{\prime \prime}(p)\left(p-c_{p}\right)<0 .
\end{aligned}
$$

Therefore, there exists a unique optimal selling price $p^{*}$ which maximizes $\prod\left(p \mid t_{1}^{*}, t_{2}^{*}\right)$ and completes the proof.

From the above analysis, we know that the solution of $g(p)+\left(p-c_{p}\right) g^{\prime}(p)=0$ is the lower bound for the optimal selling price $p$ such that $d \prod\left(p \mid t_{1}, t_{2}\right) / d p=0$. Combining Propositions 2 and 3 , we establish an algorithm to obtain the optimal policy of the considered model as follows.

Algorithm 4.

Step 1. Start with $i=0$ and let $p_{i}$ be a solution of $g(p)+(p-$ $\left.c_{p}\right) g^{\prime}(p)=0$.

Step 2. Put $p_{i}$ into (15) and (16) to obtain the corresponding values of $\left(t_{1}^{*}, t_{2}^{*}\right)$; then substitute them into (27) and determine the optimal $p_{i+1}$.

Step 3. If $\left|p_{i+1}-p_{i}\right| \leq \varepsilon$, where $\varepsilon$ is any small positive number, then set $p^{*}=p_{i+1}$ and $\left(t_{1}^{*}, t_{2}^{*}, p^{*}\right)$ is the optimal solution to minimize $\prod\left(t_{1}, t_{2}, p\right)$; otherwise, set $i=i+1$ and go back to Step 2.

\section{Numerical Examples and Sensitivity Analysis}

To demonstrate our theoretical results, we study several numerical examples to explain the algorithm proposed in the above section.

Example 1. Consider an inventory system with the following data: $A_{0}=25 \$ /$ order, $\alpha=0.03 \$, c_{p}=10.0 \$ /$ unit, $c_{d}=1.2 \$ /$ unit, $c_{h}=1.0 \$ /$ unit, $c_{0}=0.5 \$ /$ unit, $\theta=0.2, \lambda=0.3$, and $g(p)=50 e^{-0.04 p}$, where $p \in[10,+\infty)$.

For the inventory model with presale policy, by using Algorithm 4, we have $t_{1}^{*}=2.090, t_{2}^{*}=0.552, p^{*}=37.709 \$$, $Q^{*}=32.104 \$$, and $\prod\left(t_{1}^{*}, t_{2}^{*}, p^{*}\right)=209.707 \$$.

Example 2. Consider an inventory system with the following data: $A_{0}=25 \$ /$ order, $\alpha=0.05 \$, c_{p}=10.0 \$ /$ unit, $c_{d}=1.2 \$ /$ unit, $c_{h}=1.0 \$ /$ unit, $c_{0}=0.5 \$ /$ unit, $\theta=0.02, \lambda=0.6$, and $g(p)=100-5 p$, where $p \in[10,20]$.

For the inventory model with presale policy, by using Algorithm 4, we have $t_{1}^{*}=1.739, t_{2}^{*}=0.669, p^{*}=15.130 \$$, $Q^{*}=59.014 \$$, and $\prod\left(t_{1}^{*}, t_{2}^{*}, p^{*}\right)=108.783 \$$. The three-dimensional total profit per unit time graph for any given $p$ is shown in Figure 2 and the numerical results indicate that $\prod\left(p \mid t_{1}^{*}, t_{2}^{*}\right)$ is strictly concave in $p$, as shown in Figure 3 .

In order to illustrate the effect of the parameters $(\lambda, \theta, \alpha)$ on the optimal policy, that is, optimal pricing, the optimal ordering quantity, and the optimal total profit for the inventory models, the sensitivity analysis is performed on the base of Example 2 by changing the value of only one parameter at a time and keeping the rest of the parameters at their initial values. The results are shown in Table 2.

From Table 2, we can observe the following:

(1) As $\lambda$ increases, $t_{1}^{*}, Q^{*}$, and $\prod\left(t_{1}^{*}, t_{2}^{*}, p^{*}\right)$ will decrease, while $t_{2}^{*}$ and $p^{*}$ will increase simultaneously, which 
TABLE 2: The effect of parameters on the optimal policy for presale model.

\begin{tabular}{ccccccc}
\hline Para. & Value of para. & $t_{1}^{*}$ & $t_{2}^{*}$ & $p^{*}$ & $Q^{*}$ & $\Pi\left(t_{1}^{*}, t_{2}^{*}, p^{*}\right)$ \\
\hline & 0.2 & 2.792 & 0.480 & 15.086 & 80.609 & 113.323 \\
$\lambda$ & 0.4 & 2.087 & 0.594 & 15.111 & 65.851 & 110.583 \\
& 0.6 & 1.739 & 0.669 & 15.130 & 59.014 & 108.783 \\
& 0.8 & 1.517 & 0.725 & 15.246 & 54.882 & 107.431 \\
\hline & 0.01 & 1.725 & 0.744 & 15.131 & 60.532 & 109.017 \\
& 0.02 & 1.739 & 0.669 & 15.130 & 59.014 & 108.783 \\
& 0.03 & 1.749 & 0.608 & 15.128 & 57.236 & 108.542 \\
$\alpha$ & 0.04 & 1.758 & 0.557 & 15.127 & 56.752 & 108.337 \\
\hline \multirow{4}{*}{$\alpha$} & 0.04 & 1.749 & 0.608 & 15.128 & 57.685 & 108.542 \\
& 0.05 & 1.739 & 0.669 & 15.130 & 59.014 & 108.783 \\
& 0.07 & 1.728 & 0.731 & 15.136 & 60.396 & 109.128 \\
\hline
\end{tabular}

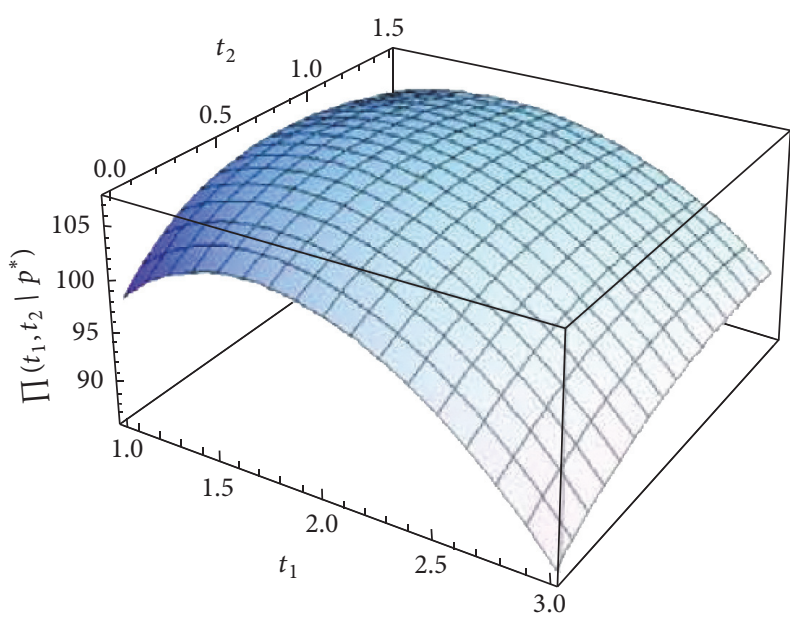

FIgURE 2: Total profit per unit time $\prod\left(t_{1}, t_{2} \mid p^{*}\right)$.

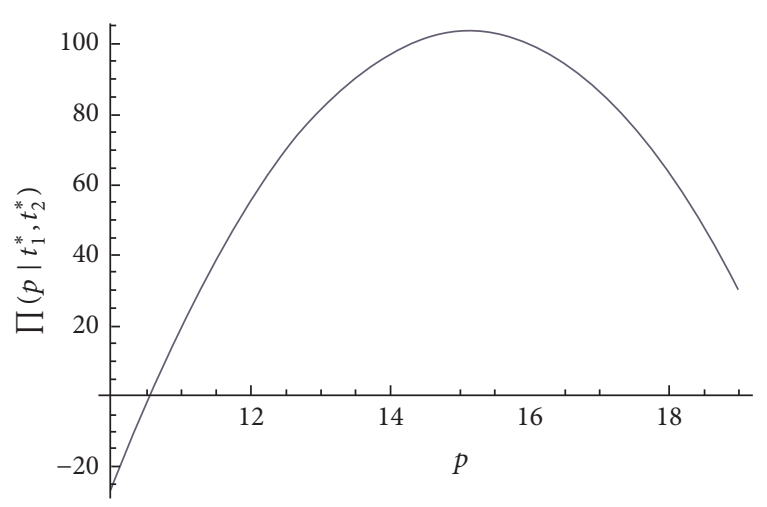

FIgURE 3: Total profit per unit time $\prod\left(p \mid t_{1}^{*}, t_{2}^{*}\right)$.

means that if the presale rebate increases, the presale period will get shorter to reduce the rebate cost. Moreover, the optimal order quantity and profit will decrease, while the selling price and spot-sale period will increase.

(2) As $\theta$ increases, $t_{2}^{*}, p^{*}, Q^{*}$, and $\prod\left(t_{1}^{*}, t_{2}^{*}, p^{*}\right)$ will decrease, and $t_{1}^{*}$ will increase. It implies that the increase in deterioration cost can lengthen the presale period and then shorten the spot-sale period. As a result, the selling price will decrease for sales promotion; moreover, the optimal order quantity and profit will decrease.

(3) As $\alpha$ increases, $t_{1}^{*}$ will decrease, and $t_{2}^{*}, p^{*}, Q^{*}$, and $\prod\left(t_{1}^{*}, t_{2}^{*}, p^{*}\right)$ will increase. It means that higher demand rate in spot-sale period will lead to shortening the presale period, while the selling price, the optimal order quantity, and profit will increase.

(4) In general, the fluctuation of $\lambda$ has more effect on $t_{1}^{*}, \Pi\left(t_{1}^{*}, t_{2}^{*}, p^{*}\right)$ than that of $\theta$ and $\alpha$, and the fluctuation of $\lambda, \theta$, and $\alpha$ each has more effect on $t_{2}^{*}, Q^{*}$ than that of $p^{*}$.

\section{Conclusion}

In this paper, we study an EOQ inventory model with presale policy for deteriorating items in which the demand rate depends on both on-hand inventory and the price of items. By analyzing the inventory model, an optimal pricing and inventory policy is proposed. We also use several numerical examples to illustrate the solution procedure. Moreover, the sensitivity analysis of the parameters is provided to assess their effects on the optimal policy of the studied problem. From the results of numerical experiments, we find that $\lambda$ and $\theta$ have a negative effect on the profit of inventory system, while $\alpha$ has a positive effect on the profit of inventory system. In addition, this paper provides an interesting topic for further study of inventory models. It also can be extended in other ways, that is, considering the nonconstant or noninstantaneous deterioration rate and others. 


\section{Competing Interests}

The authors declare that there is no conflict of interests regarding the publication of this paper.

\section{Acknowledgments}

The research is supported partly by National Natural Science Foundation of China (nos. 71502100 and 71671125).

\section{References}

[1] K.-L. Hou and L.-C. Lin, "An EOQ model for deteriorating items with price- and stock-dependent selling rates under inflation and time value of money," International Journal of Systems Science, vol. 37, no. 15, pp. 1131-1139, 2006.

[2] P.-S. You and Y.-C. Hsieh, "An EOQ model with stock and price sensitive demand," Mathematical and Computer Modelling, vol. 45, no. 7-8, pp. 933-942, 2007.

[3] C.-T. Chang, Y.-J. Chen, T.-R. Tsai, and S.-J. Wu, "Inventory models with stock- and price-dependent demand for deteriorating items based on limited shelf space," Yugoslav Journal of Operations Research, vol. 20, no. 1, pp. 55-69, 2010.

[4] C.-Y. Dye and T.-P. Hsieh, "Deterministic ordering policy with price- and stock-dependent demand under fluctuating cost and limited capacity" Expert Systems with Applications, vol. 38, no. 12, pp. 14976-14983, 2011.

[5] B. C. Giri and S. Bardhan, "Supply chain coordination for a deteriorating item with stock and price-dependent demand under revenue sharing contract," International Transactions in Operational Research, vol. 19, no. 5, pp. 753-768, 2012.

[6] J.-T. Teng and C.-T. Chang, "Economic production quantity models for deteriorating items with price- and stock-dependent demand," Computers \& Operations Research, vol. 32, no. 2, pp. 297-308, 2005.

[7] D. Panda, M. K. Maiti, and M. Maiti, "Two warehouse inventory models for single vendor multiple retailers with price and stock dependent demand," Applied Mathematical Modelling, vol. 34, no. 11, pp. 3571-3585, 2010.

[8] K. Skouri, I. Konstantaras, S. Papachristos, and I. Ganas, "Inventory models with ramp type demand rate, partial backlogging and Weibull deterioration rate," European Journal of Operational Research, vol. 192, no. 1, pp. 79-92, 2009.

[9] J. Sicilia, M. González-De-la-Rosa, J. Febles-Acosta, and D. Alcaide-López-de-Pablo, "An inventory model for deteriorating items with shortages and time-varying demand," International Journal of Production Economics, vol. 155, pp. 155-162, 2014.

[10] M. Cheng, B. Zhang, and G. Wang, "Optimal policy for deteriorating items with trapezoidal type demand and partial backlogging," Applied Mathematical Modelling, vol. 35, no. 7, pp. 3552-3560, 2011.

[11] L. Zhao, "An inventory model under trapezoidal type demand, Weibull-distributed deterioration, and partial backlogging," Journal of Applied Mathematics, vol. 2014, Article ID 747419, 10 pages, 2014.

[12] L. Zhao, "Optimal replenishment policy for weibull-distributed deteriorating items with trapezoidal demand rate and partial backlogging," Mathematical Problems in Engineering, vol. 2016, Article ID 1490712, 10 pages, 2016.

[13] R. Begum, R. R. Sahoo, and S. K. Sahu, "A replenishment policy for items with price-dependent demand, time-proportional deterioration and no shortages," International Journal of Systems Science. Principles and Applications of Systems and Integration, vol. 43, no. 5, pp. 903-910, 2012.

[14] C.-Y. Dye, "Joint pricing and ordering policy for a deteriorating inventory with partial backlogging," Omega, vol. 35, no. 2, pp. 184-189, 2006.

[15] C.-T. Yang, L.-Y. Ouyang, H.-F. Yen, and K.-L. Lee, "Joint pricing and ordering policies for deteriorating item with retail pricedependent demand in response to announced supply price increase," Journal of Industrial and Management Optimization, vol. 9, no. 2, pp. 437-454, 2013.

[16] B. Sarkar and S. Sarkar, "An improved inventory model with partial backlogging, time varying deterioration and stockdependent demand," Economic Modelling, vol. 30, pp. 924-932, 2013.

[17] G. Padmanabhan and P. Vrat, "EOQ models for perishable items under stock dependent selling rate," European Journal of Operational Research, vol. 86, no. 2, pp. 281-292, 1995.

[18] T. Avinadav, A. Herbon, and U. Spiegel, "Optimal inventory policy for a perishable item with demand function sensitive to price and time," International Journal of Production Economics, vol. 144, no. 2, pp. 497-506, 2013.

[19] R. Maihami and I. Nakhai Kamalabadi, "Joint pricing and inventory control for non-instantaneous deteriorating items with partial backlogging and time and price dependent demand," International Journal of Production Economics, vol. 136, no. 1, pp. 116-122, 2012. 

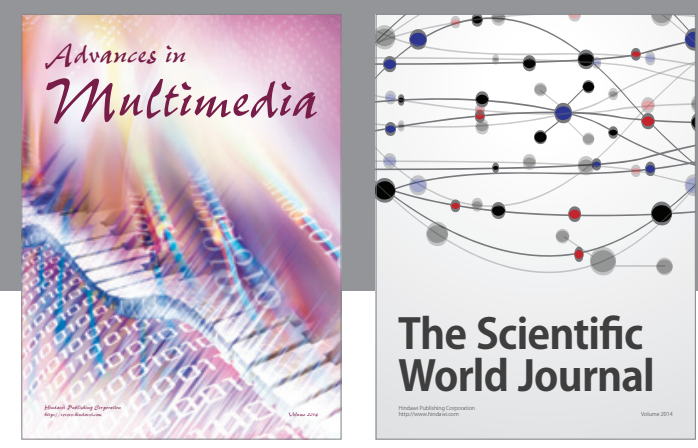

The Scientific World Journal
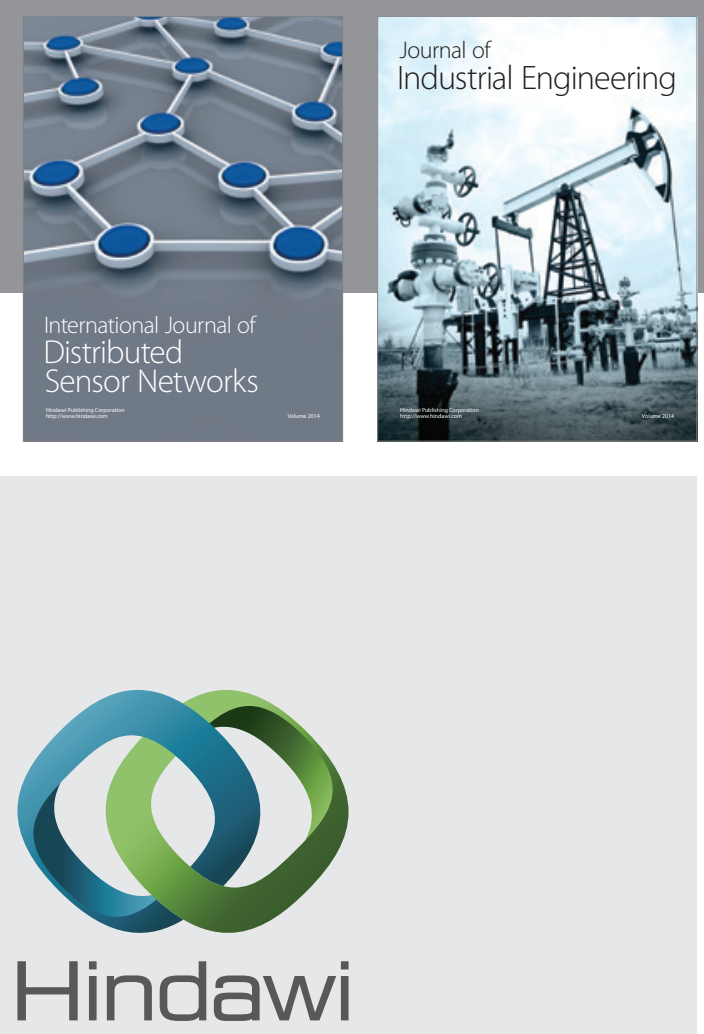

Submit your manuscripts at

http://www.hindawi.com

\section{Computer Networks} and Communications
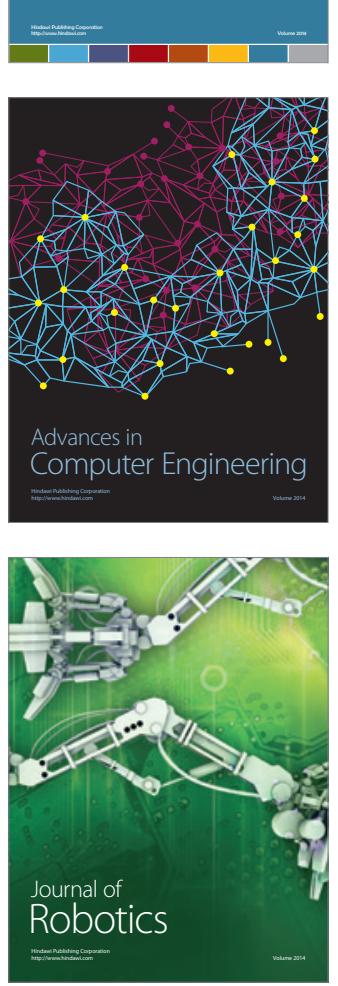
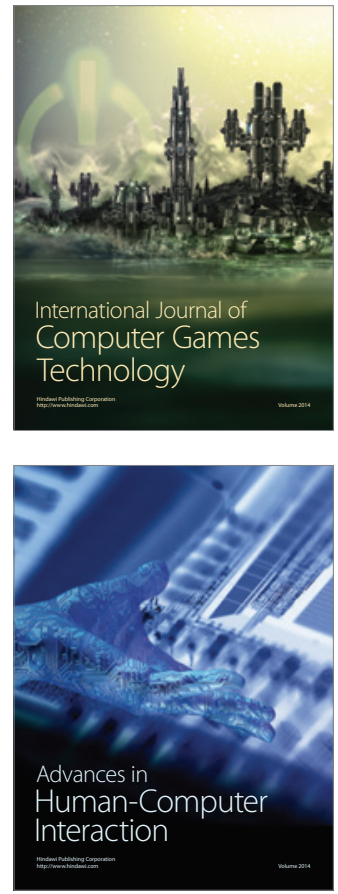
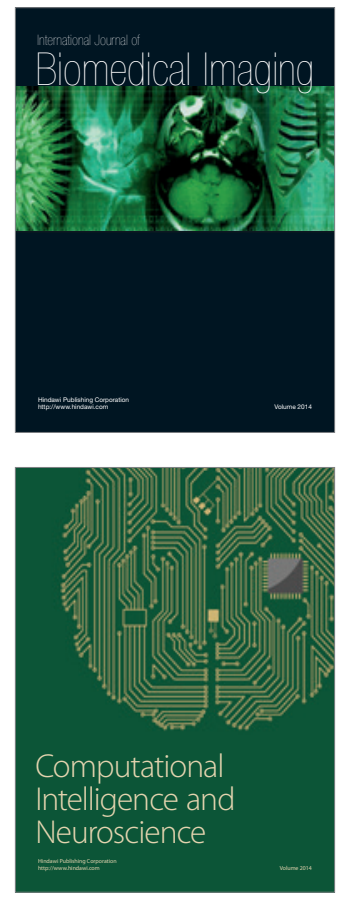
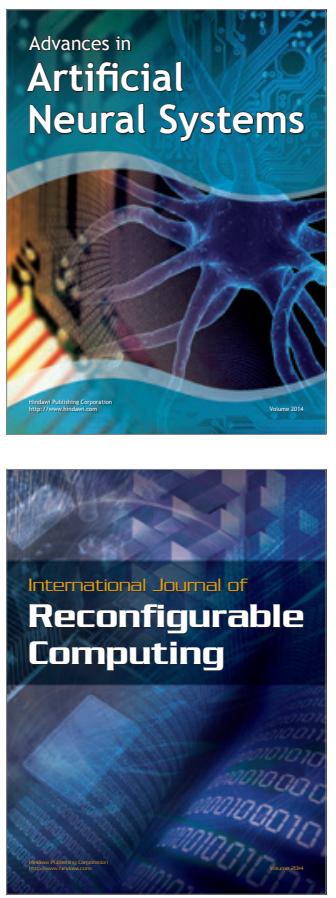
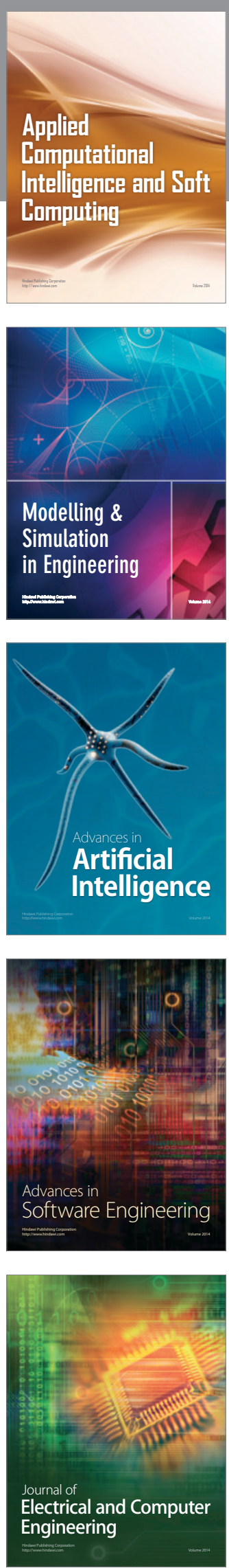